\title{
Econder
}

\author{
International Academic Journal \\ [Econder], 2020, 4 (1): 6/25
}
Türkiye'de Rekabet Gücü ve Rekabet Avantajı Konularındaki Lisansüstü Tezlerinin Bibliyometrik Profili (2000-2018)
$\&$

\section{Bibliometric Profile of Graduate Thesis on Competitive Advantage and Competitiveness in Turkey (2000-2018)}

\begin{tabular}{|c||}
\hline \hline Serkan DİLEK \\
Doç.Dr., Kastamonu Üniversitesi İ̈BF İktisat \\
serkan.dilek@gmail.com \\
Orcid ID: 0000-0002-0393-4509 \\
Hayrettin KESGİNGÖZ \\
Doç.Dr., Karabük Üniversitesi İİBF İktisat \\
Orcid ID: 0000-0002-5143-4891 \\
hayrettinkeskingoz@gmail.com \\
Onur GÜNEY \\
Kastamonu Üniversitesi SBE İktisat \\
onurguney37@icloud.com \\
\hline \hline
\end{tabular}

Makale Bilgisi / Article Information

$\begin{array}{ll}\text { Makale Türü / Article Types } & \text { : Araştırma Makalesi / Research Article } \\ \text { Geliş Tarihi / Received } & : 12-02-2020 \\ \text { Kabul Tarihi / Accepted } & : 03-20-2020 \\ \text { Yayın Tarihi / Published } & : 30-06-2020 \\ \text { Yayın Sezonu } & : \text { Haziran } \\ \text { Pub Date Season } & \text { : June }\end{array}$

Cilt / Volume: 4 Sayı - Issue: 1 Sayfa / Pages: 6-25

Atıf/Cite as: DİLEK, S , KESGINGÖZ, H , GÜNEY, O . (2020). Türkiye'de Rekabet Gücü ve Rekabet Avantajı Konularındaki Lisansüstü Tezlerinin Bibliyometrik Profili (2000-2018). Econder International Academic Journal , 4 (1) , 6-25 . Retrieved from https://dergipark.org.tr/tr/pub/econder/issue/54189/688272

Intihal /Plagiarism: Bu makale, en az iki hakem tarafından incelenmiş ve intihal içermediği teyit edilmiştir. / This article has been reviewed by at least two referees and scanned via a plagiarism software. 
Copyright (C) Published by Hayrettin KESGİNGÖZ- Karabuk University, Karabuk, 78050 Turkey. All rights reserved.

\title{
Türkiye'de Rekabet Gücü ve Rekabet Avantajı Konularındaki Lisansüstü Tezlerinin Bibliyometrik Profili (2000-2018)
}

Öz

İktisat teorisinde rekabet baskısının sayesinde piyasalarda fiyatların ve maliyetlerin düştüğü, mal kalitesinin arttı̆̆ı geçmektedir. Dolayısıyla "rekabet gücü" ve "rekabet avantajı" kavramları ile ilgili yüksek lisans ve doktora tez çalışmalarının da desteklenmesi gerektiği aşikardır. Bu çalışmanın amacı Rekabet Gücü ve rekabet avantajı alanındaki tez çalışmalarını değerlendirmektir. Bu amacı gerçekleştirmek için 2000-2018 yılları arasında başlı̆̆ında "Rekabet Gücü" ve "Rekabet Avantajı" olan yüksek lisans ve doktora tezleri Yükseköğretim Kurulu Başkanlığı'nın internet sitesinden elde edilip incelenmiştir. Tez isimlerinde "Rekabet Gücü" ve "Rekabet Avantajı" geçen 253 yüksek lisans ve 74 doktora tezi olmak üzere toplamda 327 adet tez bulunmuştur. Bu tezler üzerinde bibliyometrik bir çalışma gerçekleştirilmiştir. Rekabet gücü ve Rekabet Avantajı konularındaki tez çalışmalarında başı Gazi ve Dokuz Eylül Üniversitelerinin çektiği, 20102013 yılları arasında bu kavramlara yönelik tez sayılarının yükseldiği saptanmıştır. Üniversite, ekonomi ve işletme alanında yüksek lisans ve doktora eğitimi veren birim sayıları ele alındı̆̆ında rekabet üzerine yazılan tez sayılarının artması gerektiği görülmüştür.

Anahtar Kelimeler: Rekabet, Rekabet Gücü, Rekabet Avantajı, Tezler, Bibliyometrik, Profil

\section{Bibliometric Profile of Graduate Thesis on Competitive Advantage and Competitiveness in Turkey (2000-2018)}

\begin{abstract}
Due to competition pressure, prices and costs are decreased and quality of products is increased in economic theory. So it is clear that master thesis and dissertations about competitive advantage and competitiveness should be supported. The aim of this research is to evaluate theses about competitiveness and compettitive advantage. To this aim, master thesis and dissertations that are written about competitiveness and advantage are gotten from website of Higher Education Council and investigated. 253 master and 74 doctorate, totally 327 theses which has "Competitiveness", "Competition Power" and "Competitive Advantage" on name are found. Bibliometric study is realized on these theses. It is observed that Gazi and Dokuz Eylül universities are leading in this area and number of thesis are reached maximum number during 2010-2013. While considered number of universities and academic units that give higher education about economics and management, it is seen that number of these theses should be increased.
\end{abstract}

Keywords: Competitiveness, Competitive Advantage, Competition Power, Theses, Bibliometry, Profile

\section{GİRIŞ}

Rekabet, Adam Smith'ten bu yana iktisatçılar açısından önem taşıyan bir kavram olmaya devam etmiştir. Rekabet kavramı aynı anda hem yönetim hem de ekonomi teorisine katkı sağlayan bir kavramdır. Çoğu bilim adamı teorilerini rekabet üzerine kurmuşlardır. Klasik iktisada göre rekabet sayesinde dişsal müdahaleye gerek kalmadan piyasalar süpürülmekte ve fiyatlar marjinal maliyete eşit olmaktadır. Rekabetin fiyatları ve maliyetleri 
düşürdüğü, yenilik ve gelişmelerin ana kaynağı olduğu düşünülmektedir. Bu nedenlerden ötürü özellikle rekabet hakkında İngilizce literatür oldukça zengindir. Rekabet, Rekabet Avantajı ve Rekabet gücü kavramları iktisat ve yönetim organizasyon alanında çalışan bilim adamlarının popüler kavramlarından biri olmuştur. Türkiye'de 2000'li yıllarda üniversite sayılarının giderek arttığı, dolayısıyla bilimsel üretimin (tez, makale, kitap) arttığ1 gözlenmektedir. Türkiye'deki üniversitelerin pek çoğunun iktisat ve yönetim organizasyon alanında yüksek lisans ve doktora eğitimi veren akademik birimleri (Fakülte, Enstitü) mevcuttur.

Yüksek lisans programlarının amacı öğrencilerin bilgiye ulaşımı öğretmesi, değerlendirmesini ve yorumlama yeteneklerini kazandırmasıdır. Doktora eğitiminin amacı ise öğrencilere bağımsız araştırma yapma, bilimsel olayları geniş perspektiften bakarak değerlendirme ve sentez yapma kabiliyeti vermektir. Yüksek lisans ve doktora tezleri de öğrencilere bu yetileri kazandırmakla beraber bilimsel literatüre katkı sağlamaktadır. Lisansüstü tezlerin ve bu tezlerden üretilen makalelerin rekabet, rekabet gücü ve rekabet avantajı konularındaki literatüre ve bilimsel gelişmeye katkı sağlayacağı aşikardır.

Araştırmanın ilk aşamasında rekabet, rekabet gücü ve rekabet avantajı hakkında genel bir literatür taraması gerçekleştirilmiştir. Daha sonra bibliyometrik araştırmalar hakkında genel bilgiler verilmiştir. Son aşamada ise Türkiye'de 2001-2019 yılları arasında gerçekleştirilen lisansüstü tezler bibliyometrik yöntemler ile incelenmiştir. Bu amaçla Yükseköğretim Kurulu tez merkezi internet sitesinden tez adında "Rekabet Gücü" ve "Rekabet avantajı" bulunan lisansüstü tezler alınmış ve incelenmiştir.

\section{Rekabet, Rekabet Gücü ve Rekabet Avantajı}

Rekabetin literatürde pek çok farklı tanımı bulunmaktadır. En genel tanımlardan biri Nispeten adil bir yarışma ortamında birden çok katılımcının yarışma kurallarına bağlı olmak şartı ile eşanlı kıt olan birşeyi veya konumu elde etmek amacıyla yaptığ1 çalışmalardır (Dilek, 2017:198; Türkkan, 2001). Ayrıca üstünlük elde etmek amacıyla rakip firmalara karşı yürütülen yarışma ve mücadele süreci olarak da ele alınabilir (Ekiz, 2010:125). Tekelleri düşman diye algılayan Adam Smith'ten bu yana rekabete müspet açıdan yaklaşılmaktadır (Nickell, 1996:724). Rekabete müspet yaklaşılmasının sebebi 
olarak ekonomik etkinliği sağlaması, yenilikleri teşvik etmesi, tüketicilere seçme özgürlüğü sağlaması ve gelir dağılımında adaleti sağlaması görülebilir (Türkkan, 2016:24-28). Rekabeti bir konum yerine bir süreç olarak düşündüğümüzde firmaların davranışlarının aynı zamanda toplum için de pozitif süreçler sağlayacağını düşünebiliriz (Küçükkalay, 2008:430).

İktisat teorisine göre toplum için en fazla istenen durum tam rekabet piyasası koşulları altında sağlanabilir (Dilek, 2017:199). Özellikle klasik iktisatçılar ekonomik sistemin rekabet üzerine kurulması durumunda görünmez bir el vasıtasıyla herhangi bir dışsal müdahaleye gerek kalmaksızın ekonomik ve kaynak etkinliğinin sağlanabileceğini iddia etmektedirler. YapıDavranış-Performans (SCP) analizi ise ekonomi açısından istenen sonuçların elde edilmesi için tam rekabet koşullarının geçerli olması gerektiğini ve rekabet koşullarının sağlanması için gerekirse piyasalarda regülasyonların yapılabileceğini iddia etmektedirler. Tekel veya oligopol gibi eksik rekabet piyasalarında firmaların fiyatları yükseltme ve üretimi düşürme güçleri bulunmaktadır. Bu ise gelir dağılımı adaleti ve toplum için zararlı sonuçlara neden olmaktadır (Hatırlı, 2017). Buna ilaveten rekabet baskısı firmaları etkin üretim teknikleri kullanmaya, ortalama maliyetleri minimize etmeye cesaretlendiren temel motivasyondur (Dilek, 2017).

Piyasalarda firmalar arasındaki rekabet sürecini ve sonuçlarını açılayan anahtar kavramlardan biri de rekabet avantajıdır. Rekabet avantajını firmaların piyasalarda daha etkili rekabet edebilmesini sağlayan kaynak veya yetenek olarak tanımlamak mümkündür (Jap, 2001:19). Bir diğer tanım da piyasada firmalara sürdürülebilir üstünlük performansı sağlayan yeteneklerdir (Powell, 2001:875). Nasıl tanımlanırsa tanımlansın rekabet avantajının firmaların rakiplerinden daha üstün performans sergilemesine yardımcı olduğu açıtır. Literatürde rekabet avantajı hakkında literatürün giderek zenginleştiği görülmektedir (Powell, 2001:876). Sürdürülebilir rekabet avantajının kaynakları teknik bilgi (Johanessen ve Olsen, 2003:278), Enformasyon sistemleri (Hemmatfor et.al, 2010), düşük fiyatlar (Doğan, 2017:169), stratejik girişimcilik (Ireland ve Webb, 2007), firmaların kaynakları (Tekin ve Nas, 2017:1211), tedarik zinciri etkinliği (Yıldız ve Çetindaş, 2018:881) ve farklı diğer nedenler olabilir. Porter (1990), bazı ülkelerin diğer ülkelere karşı rekabette neden daha üstün olduğunu açıklayan elmas modelini geliştirmiştir. Bu araştırmaya göre rekabetçi avantajın dört doğrudan farklı 
kaynağı bulunmaktadır ki bunlar faktör koşulları, talep koşulları, ilgili ve destekleyici endüstriler ve firma strateji şekilleri ile endüstriyel yap1 ve rekabettir. Bunlara ilaveten iki dolaylı faktör (devlet ve şans) da rekabet avantajlarını etkilemektedir. Bu analiz, firmaların nasıl kurulduğunu, organize edildiğini ve yönetildiğini açıklamaktadır. Rekabet şekilleri de ulus ve endüstrilerin rekabetçiliğini etkilemektedir. Kaynak bazlı model firmanın sahip olduğu kaynakların onların rekabetçi avantajlarını izah ettiğini belirtmektedir (Dilek, 2017:217-218; Peteraf, 1993). Kaynak bazlı modele göre firmaların kaynakları heterojendir ve bu kaynakları elde etmek maliyetlidir (Dilek, 2017:217). Bu bakış açısına göre firmalar gelecekteki pozisyonlarını düşünerek piyasada uzun dönemli düşünerek hareket etmelidir.

Rekabet gücü, ekonomi ve yönetim literatüründe uzun yıllardır araştırılmakta ve üzerinde çalışılmaktadır (Attila, 2008). Küreselleşme nedeniyle ortaya çıkan yoğun rekabet ortamı, firmaları rekabet güçlerini artırmaya yönelik önlemler almaya mecbur etmektedir. Literatürde rekabet gücünün pek çok farklı tanımı bulunmaktadır. Rekabet gücü, firmaların diğer rakipleri ile rekabet etme kabiliyeti ve diğer rakiplerinden daha başarılı olma istekleri olarak tanımlanabilmektedir (Liargovas ve Skandalis, 2010:3). Çetindamar ve Kilitçioğlu (2013:7), rekabet gücünü firmanın günlük operasyonlarını gerçekleştirebilme potansiyeli ve yeteneği olarak tanımlamaktadır. Porter (1990) tarafından gerçekleştirilen bir diğer tanıma göre firmanın veri iş çevresinde başarılı biçimde rekabet edebilme kabiliyetidir. Kısaca rekabet, firmaların kar maksimizasyonu, büyüme, satış maksimizasyonu gibi amaçlarını gerçekleştirebilmesine yardımcı olmaktadır. $\mathrm{Bu}$ nedenle rekabet gücü firmaların üzerinde düşünmesi gereken anahtar faktörlerden biridir. Rekabet gücü, literatürde mikro ve makro olmak üzere iki farklı seviyede incelenmektedir. Makro seviyede bir ülke veya ulusun rekabetçiliği; mikro seviyede ise firmaların rekabetçiliği incelenmektedir. Rekabet gücü; stratejik yönetim ve ekonomi gibi farklı bilim dallarında araştırılan bir konudur (Çetindamar ve Kilitçioğlu, 2013:8). Rekabet gücü, firmanın etkin yönetiminin sonucunda ortaya çıkmaktadır (Liargovas ve Skandalis, 2010:18). Kaldıraç, merkezi lokasyon, firma büyüklüğü, ihracat aktivitesi, likidite, yönetim etkinliği gibi faktörlerin firma rekabet gücü üzerinde önemli etkileri bulunmaktadır (Liargovas ve Skandalis, 2010). Akben (2016:3)'e göre Türkiye'de firmaların rekabet gücünü etkileyen faktörleri analiz eden çalışmalar nicelik açısından yeterli değildir. 


\section{Bibliyometri}

Bibliyometri; kitaplar, makaleler ve diğer iletişim medya organlarının matematik ve istatistik yöntemleri kullanılarak incelenmesidir (Pritchard, 1969:348). Çoşkun vd. (2014), bibliyometriyi belirli bir bilim alanında gerçekleştirilen yayınları analiz etme ve değerlendirme avantajları sağlayan doküman analizine dayanan araştırmalar olarak tanımlamaktadır. Bibliyometrik yöntemler sayesinde bilimsel araştırmaların içerik, sonuç ve etkinliğini analiz etmek mümkün olmaktadır. Bilimsel araştırmaların bibliyometrik analizi genellikle belli bir dergide yayınlanan çalışmalar veya tezler üzerinde gerçekleştirilir. Bibliyometrik çalışmalarda bilimsel çalışmaların yazar, konu, yıl, sayfa sayısı, atıfları gibi konularda analiz edilmesi ile ilgilenmektedir. 1970'li ylllardan itibaren bibliyometrik araştırmaların sayısında artış gözlenmiştir (Yalçın, 2010:207). İlk bibliyometrik çalışmanın Dünya'da 1927 yılında; Türkiye'de ise 1970'lerde gerçekleştirildiği kabul edilmektedir (Beşel ve Yardımcıoğlu, 2017:135). Literatürde pek çok sayıda bibliyometrik araştırmaya tanıklık edilmektedir (Çoşkun et.al. 2014, Beşel and Yardımcıoğlu, 2017, Çiçek and Kozak, 2012; Yalçın, 2010; Al et.al, 2010; Hotamışlı and Erem, 2014; Demirbulat and Dinç, 2017; Depren et.al. 2018; Karagoz and Şeref, 2019; Koç et.al. 2019, Beşel, 2017).

Al vd. (2010), Bilig dergisinde yayınlanan 100 makaleyi incelemiştir. Bu araştırmanın sonucunda makalelerin çoğunun Türkçe yazıldı̆̆ı; yazarların çoğunun Gazi, Hacettepe ve Başkent üniversitelerinde çalışan akademisyenlerden oluştuğu ortaya çıkmıştır.

Yalçın (2010), Milli Folklor Dergisi'nde 2007 ile 2009 yılları arasında yayınlanan 174 makaleyi incelemiştir. Bu incelemenin sonucunda makalelerin çoğunun tek yazar tarafından yazıldığı ve Türkçe dilinin kullanıldığı ortaya çıkmıştır.

Çoşkun vd. (2014), 2008 ile 2013 yılları arasında Yükseköğretim Kurulu (YÖK) tez izleme merkezi internet sitesinde yayınlanan özel eğitim konusundaki lisansüstü tezleri incelemişlerdir. 61 yüksek lisans ve 11 doktora tezi olmak üzere toplamda 72 tez tespit edilmiştir. En fazla sayıda tez 2008 yılında yazılmıştır. Ayrıca özel eğitim konusunda en fazla tez çalışması gerçekleştiren üniversite Gazi üniversitesidir. 
Hotamışlı ve Erem (2014), Muhasebe ve Finans dergisinde yayınlanan makaleleri bibliyometrik yöntemler kullanarak analiz etmişlerdir. Bu analizin sonucunda makalelerin çoğunda finansal performans, kamu ekonomisi ve finansal piyasalar hakkında analiz edildiği ortaya çıkmıştır. Dergiye en fazla katkı sağlayan yazarların Marmara, Trakya ve İstanbul üniversitelerinden olduğu ortaya çımıştır.

Beşel ve Yardımcıoğlu (2017) 2007 ile 2016 yılları arasında Maliye dergisinde yayınlanan 330 makaleyi incelemiştir. Bu araştırmanın sonucunda ampirik çalışmaların sayısının giderek artı̆̆ğ ortaya çıkmıştır. Yaygın olarak kullanılan ekonometrik tekniklerin Augmented Dickey Fuller birim kök testi, Philips Perron birim kök testi, regresyon analizi, Johanssen eşbütünleşme testi, Granger nedensellik analizleri olduğu belirtilmiştir. Makalelerin çoğu, yardımcı doçent doktor ünvanlı yazarlar tarafından yazılmıştır.

Demirbulat ve Dinç (2017) sürdürülebilir turizm hakkında yazılan lisansüstü tezlerin bibliyometrik karakterlerini incelemişlerdir. Bu araştırmanın sonucunda sürdürülebilir turizm hakkındaki lisansüstü tezlerin çoğunluğunun İstanbul Üniversitesi'nde yazıldığı ortaya çıkmıştır. Turizm araştırmalarına olan ilginin artması sonucunda sürdürülebilir turizm hakkında yazılan lisansüstü tezlerin sayısı da artmaktadır.

Beşel (2017) Maliye alanında yazılmış olan lisansüstü tezleri bibliyometrik yöntemleri kullanarak analiz etmiştir. 2003 ile 2017 yılları arasında Yükseköğretim Kurulu (YÖK) ulusal tez merkezi sisteminde yazılmış 1714 adet tez bulunmuştur. Bu tezlerin çoğunluğunun Marmara, İstanbul ve Dokuz Eylül Üniversitelerinde yazıldığı belirlenmiştir.

Depren vd. (2018) Web of Knowledge veritabanında mevcut olan ve borsada oynaklığı konu edinen araştırmaları bibliyometrik yöntemler kullanarak incelemişlerdir. 1975 ile 2017 yılları arasında bu alanda yazılmış 7568 adet yayın bulunmuştur. Bu yayınların büyük çoğunluğu Amerika Birleşik Devletleri (ABD) ve Çin üniversitelerinde çalışan akademisyenlerce yazılmıştır. Borsada ortaya çıan oynaklık konusunu inceleyen yayınların 2005 yılı sonrasında artış kaydettiği görülmüştür.

Karagöz ve Şeref (2019) Değerleri Eğitimi dergisinde yayınlanan makalelerin bibliyometrik profilini ortaya çıkarmaya çalışmıştır. 2009 ile 2018 yılları arasında 167 adet makale bulunmuştur. Dergide yayınlanan 
makalelerin çoğunluğu iki akademisyen tarafından yazılmıştır. Dergiye katkı sağlayan yazarların çoğunluğu Sakarya Üniversitesi, Milli Eğitim Bakanlığı ve Marmara üniversitelerinden gelmektedir.

Koç vd. (2019) Marmara Üniversitesi İlahiyat Fakültesi tarafından yayınlanan Uluslararası Marmara Üniversitesi İlahiyat Fakültesi dergisinin bibliyometrik açıdan analiz etmiştir. Bu dergide yayınlanan makaleler 218'i erkek; 39'u kadın olmak üzere 257 yazar tarafından yazılmıştır. Yazarların çoğu Marmara Üniversitesi İlahiyat Fakültesi üyeleridir. Yayınların yaklaşık $\% 80$ 'i araştırma makalesidir.

\section{YÖNTEM}

$\mathrm{Bu}$ araştırma belge incelemesi yoluyla veriler toplanmıştır. Belge incelemesi yönteminde olgu veya olaylar araştıran yayınlar incelenmektedir. Genellikle röportaj, görüşme ve gözlem yoluyla veri toplamanın zor olduğu durumlarda belge incelemesi tercih edilmektedir. Bu çalışmada 2001 ile 2019 yılları arasında adında "Rekabet avantajı" ve "Rekabet gücü" kelimelerini içeren lisansüstü tezler belge incelemesi yöntemi kullanılarak analiz edilmiştir. Lisansüstü tezler hakkında bilgi toplanması amacıyla Yükseköğretim Kurulu (YÖK) ulusal tez merkezi internet sitesinden faydalanılmıştır. İsminde "Rekabet Gücü” kelimesini içeren 281 ve isminde “Rekabet avantajı" kelimesini içeren 86 adet lisansüstü tez bulunmuştur. Belirlenen bu lisansüstü tezler yayınlandığı yıl, konu, dil, üniversite ve enstitü gibi değişkenler açısından incelenmiştir. Araştırma 2001 ve 2019 yılları ile sınırlandırılmıştır. Belge incelemesi için lisansüstü tezlerin incelemesi 15.01.2020 ile 22.01.2020 tarihleri arasında gerçekleştirilmiştir. Bu amaçla Ulusal tez merkezinde tespit edilen tezler hakkındaki etiketler ve bilgiler incelenmiştir.

\section{Bulgular}

Tez adında "Rekabet Gücü" ve "Rekabet Avantajı" içeren lisansüstü tezlerin sayıları incelenmiş ve Tablo 1'de yayınlanmıştır.

Tablo 1. Lisansüstü Tezler

\begin{tabular}{|c|c|c|c|}
\hline & \multicolumn{2}{|c|}{ İsminde “Rekabet Gücü" olan Tezler } & \\
\hline & $\mathrm{N}$ & $\%$ & \\
\hline $\mathbf{B}$ conder & $\begin{array}{r}\text { EC } \\
\text { Internation } \\
\text { [Issr }\end{array}$ & c] Journal & $\begin{array}{c}\text { Cilt / Vol : 4, } \\
\text { Sayı/Issue: 1, } \\
2020\end{array}$ \\
\hline
\end{tabular}




\begin{tabular}{|l|l|l|}
\hline Yüksek Lisans & 197 & 70.1 \\
\hline Doktora & 84 & 29.9 \\
\hline Toplam & 281 & 100 \\
\hline \multicolumn{2}{|c|}{ İsminde “Rekabet Avantaj”” geçen tezler } \\
\hline & $\mathrm{N}$ & $\%$ \\
\hline Yüksek Lisans & 68 & 79.1 \\
\hline Doktora & 18 & 20.9 \\
\hline Toplam & 86 & 100 \\
\hline
\end{tabular}

2001 ile 2019 yılları arasında isminde "Rekabet Gücü" olan 281 adet lisansüstü teze rastlanmıştır. Bu tezlerin \%70.1'i yüksek lisans tezi iken \%29.9'u doktora tezidir. Yüksek lisans sonrasında Doktora eğitimine devam eden kişi sayısının düşük olması nedeniyle toplamda da yüksek lisans alanında yazılan tezlerin doktora alanında yazılan tezlere göre sayıca daha fazla olmasına neden olmaktadır. Bu nedenle "Rekabet Gücü" alanında yazılan yüksek lisans tez sayısının daha yüksek olması olağan karşılanmalıdır. Adında "Rekabet avantajı" geçen lisansüstü tez sayısı da 86'dır ve bu tezlerin sadece \%20.9'u doktora tezidir. Rekabet Gücü hakkında yazılan tez sayılarının Rekabet Avantajı hakkında yazılan tezlerden daha fazla olduğu dikkati çekmektedir. Diğer bir deyişle tez yazarları ve danışmanlar rekabet avantajı konusuna yeterince ilgi göstermemişlerdir.

Yazılan yüksek lisans ve doktora tezlerinin üniversiteleri de incelenmiş ve Tablo 2' de verilmiştir. İsminde "Rekabet Gücü" geçen 281 adet tezin yazıldığı üniversitelerde Marmara, Dokuz Eylül ve İstanbul Üniversitelerinin başı çektiği görülmektedir. Bu üç üniversite de kurulduğu yıllar itibariyle Türkiye'nin köklü üniversitelerindendir ve diğer üniversitelere nazaran daha fazla sayıda yüksek lisans ve doktora çalışması yaptırmaktadırlar. Bu yönden sonuç sürpriz karşılanmamaktadır. İsminde "Rekabet Avantajı" geçen tezlerde ise Marmara Üniversitesi'nin başı çektiği tekrar gözlenmektedir. Sürpriz olarak ise Bingöl, Çanakkale 18 Mart ve Gebze Teknik Üniversitesi'nin takipçiler olduğu görülmektedir. Bu durum daha fazla sayıda yüksek lisans ve doktora tezinin yazıldığı üniversitelerde (Dokuz Eylül, İstanbul, Ankara, Ege, Gazi vs) Rekabet Avantajı konusuna yeterince ilgi gösterilmediğinin delilidir.

Tablo 2. Üniversiteler. 


\begin{tabular}{|l|l|l|}
\hline İsminde “Rekabet Gücü" olan Tezler \\
\hline Üniversite & $\mathbf{N}$ & $\mathbf{\%}$ \\
\hline Marmara & 29 & 10.3 \\
\hline Dokuz eylül & 29 & 10.3 \\
\hline İstanbul & 20 & 7.1 \\
\hline Gazi & 11 & 3.9 \\
\hline Dumlupınar & 11 & 3.9 \\
\hline İstanbul Ticaret & 9 & 3.2 \\
\hline Selçuk & 8 & 2.8 \\
\hline Erciyes & 8 & 2.8 \\
\hline Ege & 7 & 2.5 \\
\hline Manisa Celal Bayar & 7 & 2.5 \\
\hline Diğer & 142 & 50.7 \\
\hline Toplam & 281 & 100 \\
\hline İsminde “Rekabet Avantaj1” geçen tezler \\
\hline Üniversite & $\mathbf{N}$ & $\%$ \\
\hline Marmara & 15 & 17.4 \\
\hline Bingöl & 4 & 4.7 \\
\hline Çanakkale 18 mart & 4 & 4.7 \\
\hline Gebze Teknik Üniversitesi & $4 *$ & 4.7 \\
\hline Beykent & 3 & 3.5 \\
\hline Dokuz eylül & 3 & 3.5 \\
\hline Gaziantep & 3 & 3.5 \\
\hline Ege & 3 & 3.5 \\
\hline Diğer & 47 & 54.5 \\
\hline Toplam & $\mathbf{8 6}$ & $\mathbf{1 0 0}$ \\
\hline
\end{tabular}

*Gebze Yüksek Teknoloji enstitüsü adında 3 ve Gebze Teknik Üniversitesi adı altında bir tez yazılmıştır.

Doktora tezlerinin de yazıldığı üniversiteler Tablo 3'de paylaşılmıştır. İsminde "Rekabet Gücü" geçen doktora tezlerinde de Dokuz Eylül, İstanbul ve Marmara üniversitelerinin başı çektiği görülmektedir. Rekabet Gücü konusunda yazılan toplam tezlerde Marmara Üniversitesi'nin arkasında kalan İstanbul Üniversitesi doktora tezlerinde ise öne geçmiştir. Diğer bir deyişle İstanbul Üniversitesi, doktora tez çalışmalarında Rekabet Gücü konusuna Marmara Üniversitesi'ne nazaran daha fazla önem vermiştir. İsminde 
"Rekabet Avantajı" geçen doktora tez çalışmalarında ise Çanakkale 18 Mart, Marmara ve Afyon Kocatepe Üniversitelerinin başı çektiği görülmektedir. Rekabet avantajı hakkında yazılan doktora tezlerinin sayıca yetersiz olduğu görülmektedir.

Tablo 3. Doktora Tezleri ve Üniversiteler

\begin{tabular}{|l|l|l|}
\hline \multicolumn{3}{|c|}{ İsminde “Rekabet Gücü” olan Doktora Tezleri } \\
\hline Üniversite & N & \% \\
\hline Dokuz Eylül Üniversitesi & 10 & 11.9 \\
\hline İstanbul Üniversitesi & 7 & 8.3 \\
\hline Marmara Üniversitesi & 5 & 5.9 \\
\hline Selçuk Üniversitesi & 5 & 5.9 \\
\hline Celal Bayar Üniversitesi & 4 & 4.8 \\
\hline Ege Üniversitesi & 4 & 4.8 \\
\hline Erciyes Üniversitesi & 4 & 4.8 \\
\hline Afyon Kocatepe Üniversitesi & 3 & 3.6 \\
\hline Ankara Üniversitesi & 3 & 3.6 \\
\hline Atatürk Üniversitesi & 3 & 3.6 \\
\hline $\begin{array}{l}\text { Bursa Uludağ/ } \\
\text { Üniversitesi Uludağ }\end{array}$ & 3 & 3.6 \\
\hline Dumlupınar Üniversitesi & 3 & \\
\hline Muğla Üniversitesi & 3 & 3.6 \\
\hline Süleyman Demirel Üniversitesi & 3 & 3.6 \\
\hline Diğer & 24 & 28.4 \\
\hline Toplam & 84 & 100 \\
\hline \multicolumn{1}{|c|}{ İsminde “Rekabet Avantajı” geçen Doktora tezleri } \\
\hline Üniversite & $\mathbf{N}$ & $\%$ \\
\hline Çanakkale 18 Mart Üniversitesi & 3 & \\
\hline Marmara Üniversitesi & 2 & \\
\hline Afyon Kocatepe Üniversitesi & 2 & \\
\hline Diğer & 11 & \\
\hline Toplam & 18 & \\
\hline
\end{tabular}

Yüksek Lisans ve Doktora tezlerinin yazıldığı yıllara göre de inceleme gerçekleştirilmiş ve sonuçlar Tablo 4'de paylaşılmıştır. "Rekabet Gücü" konusunda yazılan tezler 2001 ile 2012 yılları arasında dalgalı bir seyir izlemiştir. 2012 sonrası dönemde ise istikrarlı biçimde her sene artış 
kaydedilmiştir. 2012 yılında rekabet gücü hakkında yazılan tez sayısı 10 iken 2019 yılında bu sayı 32'e kadar çıkmıştır. Türkiye, küreselleşen Dünya'da giderek daha fazla dışarıya açılmakta ve ihracatını istikrarlı biçimde artırmayı amaçlamaktadır. Bunun yansıması da rekabet gücü hakkında yazılan tez sayılarında açıkça görülmektedir. İsminde "Rekabet avantajı" geçen tezlerde ise 2001 ile 2013 yılları arasında dalgalı bir seyir gözlenmektedir. Rekabet avantajı hakkında yazılan tez sayıları 2014, 2015 ve 2016 yılları arasında beşe sabitlenmişken 2017 yılında 10'a çıkmış; 2018 ve 2019 yıllarında da 10'dan daha fazla sayıda tez yazılmıştır. Rekabet Avantajı hakkında yazılan tez sayılarının da 2013 yılından itibaren artış eğilimine girdiği söylenebilir. Ancak daha önce belirtildiği gibi yine de rekabet avantajı hakkında yazılan tezler sayıca yeterli değildir.

Tablo 4. Tezlerin Yazılma Yilları

\begin{tabular}{|c|c|c|c|}
\hline & Rekabet gücü & Rekabet Avantajı & Toplam \\
\hline 2001 & 7 & 2 & 9 \\
\hline 2002 & 8 & 2 & 10 \\
\hline 2003 & 12 & 1 & 13 \\
\hline 2004 & 12 & 4 & 16 \\
\hline 2005 & 10 & 3 & 13 \\
\hline 2006 & 17 & 5 & 22 \\
\hline 2007 & 23 & 5 & 28 \\
\hline 2008 & 9 & 3 & 12 \\
\hline 2009 & 12 & 1 & 13 \\
\hline 2010 & 21 & 2 & 23 \\
\hline 2011 & 17 & 5 & 22 \\
\hline 2012 & 10 & 1 & 11 \\
\hline 2013 & 12 & 2 & 14 \\
\hline 2014 & 13 & 5 & 18 \\
\hline 2015 & 13 & 5 & 18 \\
\hline 2016 & 17 & 5 & 22 \\
\hline 2017 & 18 & 10 & 28 \\
\hline 2018 & 18 & 13 & 31 \\
\hline 2019 & 32 & 12 & 43 \\
\hline Toplam & 281 & 86 & 367 \\
\hline
\end{tabular}


İsminde "Rekabet Gücü" ve "Rekabet Avantajı" geçen doktora tezleri de yazıldıkları yıllara göre incelenmiş ve Tablo 5'de paylaşılmıştır. Doktora tezlerinde de rekabet gücü hakkında yazılan tezlerin sayısının 2018 yılında 8'e çıktığı ama 2019 yılında tekrar beşe indiği; dalgalı bir seyir izlediği görülmektedir. Rekabet avantajı konusunda ise 2007 y1lına kadar neredeyse hiç doktora tezi yazılmadığı, 2007 ile 2015 yılları arasında oldukça yetersiz miktarda doktora çalışması yapıldığı (2007 hariç ya 0 ya da 1), 2016 ve sonrasındaki dönemde ise az miktarda da olsa doktora çalışmalarının başladığı görülmektedir. Doktora tez çalışmalarında rekabet gücü ve rekabet avantajı konularına olan ilginin gelecek yıllarda artması gerektiği düşünülmektedir.

Tablo 4. Doktora Tezlerinin Yazılma Yılları

\begin{tabular}{|c|c|c|c|}
\hline & Rekabet gücü & Rekabet Avantajı & Toplam \\
\hline 2001 & 1 & 0 & 1 \\
\hline 2002 & 5 & 0 & 5 \\
\hline 2003 & 3 & 0 & 3 \\
\hline 2004 & 3 & 1 & 4 \\
\hline 2005 & 1 & 0 & 1 \\
\hline 2006 & 2 & 0 & 2 \\
\hline 2007 & 5 & 2 & 7 \\
\hline 2008 & 4 & 1 & 5 \\
\hline 2009 & 6 & 0 & 6 \\
\hline 2010 & 6 & 0 & 6 \\
\hline 2011 & 6 & 1 & 7 \\
\hline 2012 & 5 & 0 & 5 \\
\hline 2013 & 6 & 1 & 7 \\
\hline 2014 & 4 & 1 & 5 \\
\hline 2015 & 4 & 0 & 4 \\
\hline 2016 & 5 & 4 & 9 \\
\hline 2017 & 5 & 3 & 8 \\
\hline 2018 & 8 & 1 & 9 \\
\hline 2019 & 5 & 3 & 8 \\
\hline Toplam & 84 & 18 & 102 \\
\hline
\end{tabular}


İsminde "Rekabet Gücü" ve “Rekabet Avantajı” geçen tezler yazıldıkları dil itibariyle de incelenmiş ve sonuçlar Tablo 5'de paylaşılmıştır. Tezlerin büyük çoğunluğu Türkçe yazılmıştır. İkinci sırada İngilizce bulunmaktadır. Rekabet avantajı konusunda yazılan tezlerin İngilizce oranının Rekabet gücü hakkında yazılan tezlerin İngilizce oranına göre daha yüksek olduğu görülmektedir. Rekabet avantajı hakkında yazılan tezlerin \%19.8'i; Rekabet gücü hakkında yazılan tezlerin ise \%4.6'sı İngilizce yazılmıştır.

Tablo 5. Tezler ve Yazıldıkları diller

\begin{tabular}{|l|l|l|}
\hline & Rekabet gücü & Rekabet avantaj1 \\
\hline Türkçe & 267 & 68 \\
\hline İngilizce & 13 & 17 \\
\hline Almanca & 1 & 1 \\
\hline Toplam & 281 & 86 \\
\hline
\end{tabular}

İsminde "Rekabet Gücü" ve "Rekabet Avantajı" geçen tezlerin danışmanlarının ünvanları incelenmiş ve sonuçlar Tablo 6'da paylaşılmıştır. Üniversitelerde danışmanlıklar özellikle de doktora tez danışmanlıkları Prof.Dr. ünvanlı akademisyenler tarafından gerçekleştirilmektedir. Bu nedenle rekabet gücü ve rekabet avantajı konularındaki tezlerin danışmanlıklarında da Prof.Dr. ünvanlı akademisyenlerin oranının yüksek olduğu görülmektedir. Rekabet Gücü hakkındaki tezlerin \%50.3'ünün; Rekabet avantajı hakkındaki tezlerinde \%42.5'inin danışmanlığı Prof.Dr. ünvanlı akademisyenler tarafından yürütülmüştür. Doktora tez danışmanlıklarında ise bu oran daha da yükselmektedir. İsminde "Rekabet Avantajı" geçen doktora tezlerinde danışmanların 2 tanesi Yrd.Doç.Dr., Dr.Öğr.Üyesi ünvanlarına sahipken 6 tanesi Doç.Dr. ve 10 tanesi de Prof.Dr. ünvanına sahiptir (Prof.Dr. oranı \%55.5). İsminde "Rekabet Gücü" geçen tezlerde ise danışmanların sadece 4 tanesi Yrd.Doç.Dr./Dr.Öğr.Üyesi, 18 tanesi Doç.Dr. ve 62 tanesi Prof.Dr. ünvanına sahiptir (Prof.Dr. oranı \%73.8).

Tablo 6. Danışmanlıklar

\begin{tabular}{|l|l|l|}
\hline & Rekabet gücü & Rekabet avantaji \\
\hline $\begin{array}{l}\text { Dr.Öğr.Üyesi/Yrd. } \\
\text { Doç.Dr./ Dr }\end{array}$ & 86 & 25 \\
\hline
\end{tabular}




\begin{tabular}{|l|l|l|}
\hline Doç.Dr. & 56 & 25 \\
\hline Prof.Dr. & 144 & 37 \\
\hline Toplam & $286^{*}$ & $87^{*}$ \\
\hline
\end{tabular}

*Bazı tezlerde çift danışman vardır. Tüm danışmanlar ele alınmıştır.

Rekabet gücü ve Rekabet Avantajı tezlerinin yazıldığı anabilim Dalları da incelenmiş ve Tablo 7'de paylaşılmıştır. Rekabet Gücü hakkında yazılan tezlerin büyük çoğunluğu İktisat ve İşletme Anabilim Dallarında yazılmıştır. 281 adet tezin sadece \%27'si diğer anabilim dallarında yazılmıştır. Ayrıca diğer anabilim dalları arasında Maliye, Turizm İşletmeciliği gibi iktisat ve işletme $A B D$ ile yakın ilişkide bulunan $A B D$ vardır. İktisat ABD'nın İşletme ABD'dan daha fazla ilgi gösterdiği görülmektedir. İlginç olan sonuç ise Rekabet Avantajı hakkında yazılan 86 tezin sadece 4'ünün İktisat ABD tarafından yazılmasıdır. Rekabet avantajı konusuna İktisat ABD yüksek lisans ve doktora çalışması yapan öğrenciler ile danışman öğretim üyelerinin ilgi göstermediği görülmektedir.

Tablo 7. Ana Bilim Dalları

\begin{tabular}{|l|l|}
\hline İsminde “Rekabet Gücü” Geçen tezlerde ABD \\
\hline İktisat & 122 \\
\hline İşletme & 83 \\
\hline Diğer & 76 \\
\hline Toplam & 281 \\
\hline İsminde “Rekabet Avantaj1” geçen tezlerin ABD \\
\hline İktisat & 4 \\
\hline İşletme & 59 \\
\hline Diğer & 23 \\
\hline Toplam & 86 \\
\hline
\end{tabular}

*: bazı tezlerin künyelerinde ABD yazmıyor. Bunlarda anahtar kelimeler ve öğretim üyesinin kadrosundan çıkarsama yapılmıştır.

Adında "Rekabet Gücü" ve "Rekabet Avantajı" geçen tezlerin sayfa sayıları da incelenmiş ve sonuçları Tablo 8'de paylaşılmıştır. Tezlerin büyük çoğunluğunun sayfa sayılarının 101 ile 200 sayfa arasında olduğu ortaya çıkmıştır. Rekabet gücü ile ilgili tezlerin \%53.7'si; Rekabet avantajı ile ilgili tezlerin ise \%66.3'ü, 101 ile 200 sayfa arasında uzunluktadır.

Tablo 8. Sayfa Sayıları 


\begin{tabular}{|l|l|}
\hline $\begin{array}{l}\text { İsminde “Rekabet Gücü” Geçen tezler sayfa } \\
\text { sayıları }\end{array}$ \\
\hline 0-100 sayfa & 35 \\
\hline 101-200 sayfa & 151 \\
\hline 201 ve daha yukarısı & 95 \\
\hline Toplam & 281 \\
\hline $\begin{array}{l}\text { İsminde “Rekabet Avantaj1” geçen tezler Sayfa } \\
\text { sayıları }\end{array}$ \\
\hline 0-100 sayfa & 11 \\
\hline 101-200 sayfa & 57 \\
\hline 201 ve daha yukarıs1 & 18 \\
\hline Toplam & 86 \\
\hline
\end{tabular}

Rekabet gücü ve rekabet avantajı ile ilgili tezlerin yazıldığ 1 tezlerin yazıldıkları enstitüye göre dağılımları ise Tablo 9'da verilmiştir. Bu tezlerin büyük çoğunluğunun Sosyal Bilimler Enstitüsü'nde yazıldıkları ortaya çıkmıştır. Rekabet Avantajı ile ilgili tezlerin \%89.5'i; rekabet gücü ile ilgili tezlerin \%85.8'i Sosyal Bilimler Enstitüsünde yazılmıştır. Bu sonucun tezlerin yazıldığı anabilim dallarının iktisat ve işletme ile ilgili olmasına dayandığ1 görülmektedir.

Tablo 9. Tezlerin Enstitülere Göre Dağılımı

\begin{tabular}{|l|l|l|}
\hline ENSTİTÜLER & $\begin{array}{l}\text { Rekabet } \\
\text { Avantaj1 }\end{array}$ & Rekabet Gücü \\
\hline Sosyal Bilimler Enstitüsü & 77 & 241 \\
\hline Fen Bilimleri Enstitüsü & 7 & 26 \\
\hline $\begin{array}{l}\text { Diğger Enstitülerin } \\
\text { Toplamı }\end{array}$ & 2 & 14 \\
\hline Toplam & 86 & 281 \\
\hline
\end{tabular}




\section{SONUÇ}

Küreselleşme ve gelişen ulaştırma imkânları uluslararası ticaretin gelişmesine neden olmuş; ülkeler ve firmalar arasındaki rekabet daha önemli hale gelmiştir. Bunun sonucunda rekabet gücü ve rekabet avantajı konularında yazılan bilimsel eserlerin sayısının giderek arttığ gözlenmektedir. 2001 ile 2019 yılları arasında isminde "Rekabet Gücü" ve "Rekabet Avantajı" içeren tezler bibliyometrik yöntemler ile incelenmiştir. Bu incelemeler aşağıdaki sonuçlara ulaşılmasını sağlamıştır.

a) İsminde "Rekabet Gücü" geçen tezlerin sayısı isminde "Rekabet avantajı" geçen tezlerin sayısından daha yüksektir. Bu yüksek lisans ve doktora öğrencileri ile danışman öğretim üyelerinin rekabet gücü kavramına daha fazla ilgi gösterdiği biçiminde yorumlanabilir. Aynı zamanda rekabet avantajı konusuna yeteri kadar ilgi göstermediği de görülmektedir.

b) İsminde "Rekabet Gücü" ve "Rekabet avantajı" geçen yüksek lisans tez sayısı doktora tez sayısından daha fazladır. Bu durum doktora tez sayılarının ve doktora yapan öğrenci sayılarının daha düşük olması ile doğru orantılıdır.

c) İsminde "Rekabet Gücü" geçen tezlerin yazıldığ 1 üniversitelerde Marmara, Dokuz Eylül, İstanbul, Gazi ve Dumlupınar üniversitelerinin başta geldiği görülmektedir. $\mathrm{Bu}$ üniversiteler çok sayıda yüksek lisans ve doktora öğrencisine eğitim veren Türkiye'nin köklü üniversiteleridir. Dolayısıyla bu üniversitelerin rekabet gücü hakkında daha fazla lisansüstü tez çalışması yaptırması beklenmedik bir sonuç değildir.

d) İsminde "Rekabet avantajı" geçen tezlerin yazıldığı üniversitelerde Çanakkale 18 Mart, Marmara ve Afyon Kocatepe üniversitelerinin başta geldiği görülmektedir. Marmara üniversitesi haricinde fazla sayıda yüksek lisans ve doktora öğrenciye eğitim veren üniversitelerin rekabet avantajı konusuna lisansüstü tez çalışmalarında yeteri kadar önem vermediği görülmüştür.

e) 2016 yılı ve sonrasında isminde "Rekabet Gücü" ve "Rekabet Avantajı" olan lisansüstü tez sayılarında artış gözlenmiştir. Bu durum yüksek lisans ve doktora öğrencileri ve danışman öğretim üyelerinin Rekabet gücü ve rekabet avantajı konularına olan ilgilerinin arttığını göstermektedir. 
f) İsminde "Rekabet Gücü" ve "Rekabet Avantajı" içeren tezlerin büyük çoğunluğunun Türkçe yazıldığı ikinci sırada İngilizce dilinin olduğu görülmüştür. Rekabet avantajı konusunda yazılan tezlerde İngilizce kullanma oranının Rekabet gücü hakkındaki tezlerde İngilizce kullanma oranından yüksektir.

g) İsminde "Rekabet Gücü" ve "Rekabet avantajı" içeren tezlerin danışmanlığını yapan öğretim üyeleri arasında Prof.Dr. ünvanına sahip akademisyenlerin başta geldiği görülmektedir. Doktora tezlerinde ise danışmanlıklarda Prof.Dr. ünvanlı kişilerin oranı daha yükselmektedir. Bu sonuçlar Prof.Dr. ünvanına sahip öğretim üyelerinin lisansüstü çalışmalara daha fazla yönelmesi ve tez danışmanlıklarına daha fazla ilgi göstermesine bağlıdır.

h) İsminde "Rekabet Gücü" olan tezlerin büyük çoğunluğu İktisat ve İşletme ABD'larında yazılmıştır. İktisat ABD'nın daha fazla ilgi gösterdiği görülmüştür. Bu tezleri yazıldığı diğer ABD'larının sayısı oldukça düşüktür ve bu ABD'larının bir kısmı İktisat ve işletme ile yakın ilişkili olan (Maliye, Uluslararası Ticaret, Turizm İşletmeciliği vb) ABD'larıdır. Diğer bir deyişle rekabet gücü kavramına iktisat ve işletme konularında çalışan bilim adamlarının daha yoğun ilgi gösterdiği görülmektedir.

i) İsminde "Rekabet avantajı" olan tezlerin büyük çoğunluğu İşletme ABD'nda yazılmıştır. Rekabet gücü konusuna büyük önem veren İktisat $\mathrm{ABD}$ 'nın rekabet avantajına ise yeteri kadar ilgi göstermediği görülmüştür.

j) İsminde "Rekabet Gücü" ve "Rekabet Avantajı" içeren tezlerin büyük çoğunluğu 101 ile 200 sayfa arasında uzunluktadır.

k) İsminde "Rekabet Gücü" ve "Rekabet avantaj1" içeren tezlerin büyük çoğunluğu Sosyal Bilimler Enstitüsü'nde yazılmaktadır. Bunun nedeni İktisat ve İşletme ABD’larının konuya ilgi göstermesidir.

İlerideki akademik çalışmalarda seçilmiş dergilerde rekabet gücü ve rekabet avantajı konularında yapılan akademik çalışmalar ele alınabilir. Ayrıca rekabet gücü ve rekabet avantajı konularında lisansüstü tezlerin desteklenmesi gereklidir. 


\section{KAYNAKÇA}

Akben-Selcuk, E. (2016). Factors affecting firm competitiveness: Evidence from an emerging market. International Journal of Financial Studies, 4(2), 9.

Al, U., Soydal, İ ve Yalçın H. (2010), “Bibliyometrik Özellikleri Açısından Bilig' in Değerlendirilmesi", Bilig, 55, 1-20

Attila Chikán, (2008),"National and firm competitiveness: a general research model", Competitiveness Review: An International Business Journal, Vol. 18 Iss $1 / 2$ pp. $20-28$

Beşel, F. \& Yardımcıoğlu, F. (2017). Maliye Dergisinin Bibliyometrik Analizi 2007-2016 Dönemi. Maliye Dergisi. 172, 133-151.

Cetindamar, D. \& Hakan Kilitcioglu, (2013),"Measuring the competitiveness of a firm for an award system", Competitiveness Review: An International Business Journal incorporating Journal of Global Competitiveness, Vol. 23 Iss: 1 pp. $7-22$

Çiçek, D., \& Kozak, N. (2012). Anatolia: Turizm Araştırmaları Dergisi'nde yayımlanan hakem denetimli makalelerin bibliyometrik profili. Türk Kütüphaneciliği, 26(4), 734-756.

Coşkun, İ., Dündar, Ş. ve Parlak, C. (2014), Türkiye'de Özel Eğitim Alanında Yapılmış Lisansüstü Tezlerin Çeşitli Değişenler Açısından İncelenmesi (2008-2013). Ege Eğitim Dergisi, 15(2), 375-396

Demirbulat, Ö. G., \& Dinç, N. T. (2017). Sürdürülebilir turizm konulu lisansüstü tezlerin bibliyometrik profili. Seyahat ve Otel Işsletmeciliği Dergisi, 14(2), 20-30.

Depren, Ö., Kartal, M. T., \& DEPREN, S. K. (2018). Borsalarda Oynaklık Üzerine Yayınlanmış Akademik Çalışmaların Bibliyometrik Analizi. Bankacılık ve Sermaye Piyasası Araştırmaları Dergisi, 2(6), 1-15.

Dilek, S. (2017). Oyun Teorisi Eşliğinde Sanayi Ekonomisi. Seçkin Yayınları

Doğan, E. (2017). Rekabet Stratejileri Perspektifinden Sürdürülebilir Rekabet Üstünlüğü. Yönetim ve Ekonomi Araştırmaları Dergisi. 15, 163-178.

Ekiz, Cengiz (2010). Türkiye'de Rekabet Yönetimi: Tekelci Düzenlemenin Ekonomi Politiği, Siyasal Kitabevi

Hatırlı, S.A. (2017). Mikroekonomi. Alter Yayınları.

Hemmatfor, M.H., Salehi, M. \& Bayat, M. (2010). Competitive Advantages and Strategic Information Systems. International Journal of Business and Management, 5(7), 158-169 
Hotamışl1, M., \& Erem, I. (2014). Muhasebe ve Finansman Dergisi'nde yayınlanan makalelerin bibliyometrik analizi. Muhasebe ve finansman dergisi, (63), 1-20.

Ireland, R.D. \& Webb, J.W. (2007). Strategic Entrepreneurship: Creating Competitive Advantage Through Streams of Innovation. Business Horizons. 50, 49-59.

Jap, S.D. (2001). Perspectives On Joint Competitive Advantages In BuyerSupplier Relationships. International Journal of Research in Marketing. 18, 19-35.

Johanessen, J.A. \& Olsen, B. (2003). Knowledge Management and Sustainable Competitive Advantages:The Impact of Dynamic Contextual Training. International Journal of Information Management. 23, 277-289.

Karagöz, B. \& Şeref, İ. (2019). Değerler Eğitimi Dergisi'nin bibliyometrik profili (2009-2018). Değerler Eğitimi Dergisi, 17 (37), 219-246

Liargovas, P., \& Skandalis, K. (2010). Factors affecting firm competitiveness: The case of Greek industry. European institute Journal, 2(2), 184-197.

Nickell, S.J. (1996). Competition and Corporate Performance. Journal of Political Economy.104(4), 724-746

Peteraf, M.A. (1993). The Cornerstones of Competitive Advantage: A Resource Based View. Strategic Management Journal. 14, 179-191.

Porter, M. E. (1990). The Competitive Advantage of Nations. New York, NY: The Free Press

Powell T. (2001). Competitive advantage: logical and philosophical considerations. Strategic Management Journal. 22(9), 875-888

Pritchard, A. (1969). Statistical bibliography or bibliometrics? Journal of Documentation, 25, 348-349

Tekin, E , İlhan Nas, T . (2017). Firma ve Üst Düzey Yönetici Özelliklerinin Türkiye'de Faaliyette Bulunan KOBİlerin İhracat Performansı Üzerindeki Etkisi. Ankara Üniversitesi SBF Dergisi , 72 (4) , 1185-1217

Türkkan, Erdal (2016), Ekonomide ve Siyasette Adil Rekabet, Orion Yayınları Türkkan, E. (2001). Rekabet Teorisi ve Endüstri İktisadı. Turhan Yayınevi.

Yalçin, H. (2010). Millî Folklor dergisinin bibliyometrik profili (2007-2009). Millî Folklor, 22(85), 205-211.

Yıldız B.\& Çetindaş A. (2018), Stratejik Kaynak Kullanımının Firma Performansı Üzerindeki Etkisinde Tedarik Zinciri Çevikliğinin Aracı Rolü, BMIJ, (2018), 6(4): 878-897. 